\title{
Analisis Video Share to Likes Ratio Pada 6 Brand Fashion Terkenal
}

\author{
I Made Yoga Apriliana Putra
}

19101112

madeyoga558@gmail.com

\begin{abstract}
TikTok is a social media application launched by a Chinese company. TikTok allows users to create 15 -second videos accompanied by music, filters, and several other creative features. The increasing number of TikTok users has made many world brands use TikTok as a media to promote the products they sell. The 6 Famous Fashion Brands that use TikTok as a medium for promotion are: Vessi, Gymshark, Levi's, Crocs, Calvin Klein and Guess. The purpose of this study is to determine the credibility of the performance of the TikTok account of 6 Famous Fashion Brands using the Video Share to Likes Ratio. The method used is quantitative exploratory to determine the credibility of the TikTok account performance of 6 Famous Fashion Brands. The results of this study indicate that Crocs is ranked first and has good performance credibility.
\end{abstract}

\begin{abstract}
ABSTRAK
TikTok merupakan aplikasi sosial media yang diluncurkan oleh perusahaan asal Tiongkok. TikTok memungkinkan penggunanya membuat video berdurasi 15 detik yang disertai dengan musik, filter, dan beberapa fitur kreatif lainnya. Pengguna TikTok yang semakin meningkat membuat banyak brand-brand dunia yang memanfaatkan TikTok sebagai media promosi produk yang mereka jual. Adapun 6 Brand Fashion Terkenal yang meanfaatkan TikTok sebagai media untuk promosi yaitu: Vessi, Gymshark, Levi's, Crocs, Calvin Klein dan Guess. Tujuan dari penelitian ini adalah untuk mengetahui kredibilitas performa dari akun TikTok 6 Brand Fashion Terkenal menggunakan Video Share to Likes Ratio. Metode yang digunakan adalah eksploratif kuantitatif untuk mengetahui kredibilitas dari performa akun TikTok 6 Brand Fashion Terkenal. Hasil dari penelitian ini menjukan bahwa Crocs mendapat peringkat pertama dan memiliki kredibilitas performa yang baik.
\end{abstract}

Keyword: Credibility Account TikTok; Social Media Marketing; Social Media TikTok;

Video Share to Likes Ratio; Brand Fashion Terkenal

\section{PENDAHULUAN}

Teknologi informasi dan komunikasi yang berkembang dengan sangat pesat memberikan berbagai dampak pada kegiatan manusia, salah satunya dalam bidang komunikasi yang dahulu dilakukan secara fisik (surat, tatap muka), sekarang dapat dilakukan secara online melalui platform media sosial yang ada. Media sosial memiliki banyak manfaat dalam keseharian masyarakat diantaranya untuk berkomunikasi jarak jauh, mencari informasi terbaru ataupun menyalurkan hobi. 
Dengan adanya perkembangan teknologi yang begitu pesat ini membuat membuat banyak aplikasi-aplikasi sosial baru yang bermunculan, dari yang awalnya hanya untuk chat, telephone, dan email. Namun saat ini sudah banyak aplikasi yang menambahkan fitur-fitur baru seperti berbagi video, foto, ataupun live steaming. Salah satu media sosial yang sedang ramai digunakan adalah TikTok. TikTok merupakan aplikasi yang diluncurkan oleh perusahaan asal Tiongkok. TikTok memuungkinkan penggunanya membuat video berdurasi 15 detik yang disertai dengan music, filter, dan beberapa fitur kreatif lainnya (Adawiyah 2020).

Kehadiran media sosial TikTok dapat membangun sebuah brand, TikTok juga dapat membangun personal branding pemiliknya (Ishihara dan Oktavianti 2021). Pengguna TikTok yang semakin meningkat membuat banyak brand-brand dunia yang memanfaatkan TikTok sebagai media promosi produk yang mereka jual. Sangat banyak brand-brand dunia yag telah melakukan promosi melalui TikTok, contohnya seperti brand fashion dunia. Adapun 6 Brand Fashion Terkenal, diantaranya yaitu: Vessi, Guess, Gymshark, Calvin Klein, Crocs, dan levi’s ("15 brand yang menggunakan TikTok untuk Pemasaran - www.maxmanroe.com")

Penelitian ini menggunakan metode eksploratif kuantitatif, dan akan menghitung menggunakan rasio-rasio yang ada pada TikTok. Pada penelitian (Permana dan Meinarni 2021) menjelaskan bahwa terdapat 17 rasio yang ada pada sosial media TikTok dan relevan digunakan sebagai media ukur kredibilitas akun yang ada. Penelitian ini hanya berfokus pada penghitungan kredibilitas Video Share to Likes Ratio pada 6 Brand Fashion Terkenal. Adapun 6 brand fashion terkenal dunia, diantaranya yaitu: Vessi, Guess, Gymshark, Calvin Klein, Crocs, dan Levi’s ("15 brand yang menggunakan TikTok untuk Pemasaran - www.maxmanroe.com"). Tujuan dari penelitian ini adalah untuk mengetahui kredibilitas performa dari akun TikTok 6 Brand Fashion Terkenal menggunakan Video Share to Likes Ratio.

\section{TINJAUAN PUSTAKA}

Pesatnya perkembangan pada bidang teknologi saat ini menyebabkan banyaknya aplikasiaplikasi serta platform media sosial yang bermunculan. Aplikasi yang sedang tren saat ini diantaranya yaitu TikTok, Instagram, WhatsApp, dan lain sebagainya. Saat ini pengguna aplikasi sosial media tidak hanya para remaja tetapi orang tua dan anak-anak pun banyak yang menggunakan media sosial. Hal ini cukup berbahaya bagi anak-anak jika tidak diawasi oleh orang yang lebih dewasa, karena dapat menyebabkan kecanduan dan tidak bisa bersosialisasi dengan orang di lingkunganya.

TikTok merupakan salah satu aplikasi yang terbilang baru release/diluncurkan. TikTok merupakan aplikasi media sosial yang umumnya membagikan video dengan durasi 15 detik. Pada aplikasi TikTok pengguna dapat membuat video dengan filter-filter yang special serta menggunakan lagu yang sedang trending. Selain itu, pengguna dapat membagikan video yang dibuat keaplikasi lain seperti Instagram ataupun Twitter (PRIANBODO 2018). 
Aplikasi TikTok tidak hanya untuk membuat konten video dengan tujuan menghibur pengguna lainnya. Aplikasi TikTok juga dapat dijadikan peluang bagi brand atau perusahaan sebagai platform social media marketing. TikTok memiliki keuntungan dalam kegiatan promosi seperti memberikan informasi yang memadai tanpa biaya tinggi, tenaga banyak, dan dapat dilakukan dalam waktu yang relatif singkat (Bayu Dewa \& Ayu Safitri 2021).

TikTok dirasakan memiliki pengaruh dalam industry, sehingga menimbulkan kualitas akun yang menentukan strata maupun kredibilitas pemilik akun. Kredibilitas akun TikTok merupakan suatu hal yang cukup penting untuk berbagai kepentingan. Kredibilitas sebuah akun TikTok dapat diukur dari tingkat performa yang dihasilkan secara sistematis. Dalam mengukur performa diperlukan skala pengukuran yang tertuang kedalam ratio.

\section{METODE PENELITIAN}

Penelitian ini menggunakan metode eksploratif kuantitatif untuk mengetahui kredibilitas dari performa akun TikTok 6 Brand Fashion Terkenal. Metode eksploratif merupakan penelitian yang memiliki tujuan untuk melakukan eksplorasi atau memperdalam pengetahuan ataupun ideide baru mengenai suatu hal yang baru, guna merumuskan permasalahan secara terperinci (Maryam, Isrok'atun, and Aeni 2016).

Tujuan dari penelitian ini yaitu mengetahui nilai kredibillitas dari performa akun TikTok 6 Brand Fashion Terkenal. Ada beberapa langkah yang harus dilakukan dalam penelitian ini, sehingga mampu menentukan peringkat pertama akun TikTok 6 Brand Fashion Terkenal yang memiliki performa terbaik. Langkah-langkah yang dilakukan pada penelitian ini yaitu:

1. Melakukan Eksplorasi Pada Website Untuk Menentukan Objek yang Akan Dianalisa.

Eksplorasi ini dilakukan pada beberapa halaman website yang menyediakan informasi mengenai objek yang akan di teliti. Setelah ekslorasi selesai dilakukan, sehingga ditemukan namanama Brand Fashion Terkenal yang akan dijadikan objek analisa. Setelah melakukan eksplorasi pada halaman website, maka langkah selanjutnya yaitu mencari nama akun TikTok dari masingmasing brand fashion. Pastikan semua brand memiliki akun pada aplikasi sosial media TikTok.

2. Menghitung Nilai Rata-Rata Variable Dari 6 Brand Fashion Terkenal

Pada langkah ini, peneliti menghitung nilai variabel Video Share to Likes. Variabel merupakan sesuatu yang memiliki nilai bervariasi dimana nilai tersebut dapat dijadikan sebagai dasar untuk empat data yang berbeda seperti rasio, skala, ordinal, nominal dan internal (Rankuti 2015). Untuk menghitung variable Video Share to Likes yaitu dengan mengambil setidaknya 10 postingan terbaru dan menghitungnya hingga hasil rata-ratanya ditemukan.

3. Menghitung Nilai Kredibilitas Rasio

Untuk menghitung nilai kredibilitas dari video share to likes ratio, peneliti menggunakan cara membagi nilai variabel pertama dengan nilai variabel kedua. Jika video share memiliki nilai 600 dan likes memiliki nilai 100, maka cara menghitungnya yaitu 600:100 $=6$. Dengan begitu nilai dari video share to likes ratio adalah 6 . 


\section{Menentukan Peringkat Pada Akun TikTok}

Pada langkah terakhir yang dilakukan pada penelitian ini yaitu menentukan peringkat pada masing-masing rasio yang ada. Pada penentuan peringkat perlu melihat karakteristik dari rasio yang di teliti. Jika karakteristik rasio merupakan rendah, maka objek yang memiliki nilai terendah akan mendapatkan angka 5 dan objek yang memiliki nilai tertinggi akan mendapatkan angka 1. Namun jika rasio memiliki karakteritik tinggi maka objek yang mendapatkan nilai tinggi akan mendapatkan angka 5 dan objek yang mendapatkan nilai terendah akan mendapatkan angka 1. Setelah mendapatkan hasil kredibilitas ratio maka dapat disimpulkan objek yang mana mendapatkan peringkat 1 sampai dengan peringkat 5 .

\section{HASIL DAN PEMBAHAN}

Akun Tiktok dari 6 Brand Fashion Terkenal, diantaranya:

1. Crocs

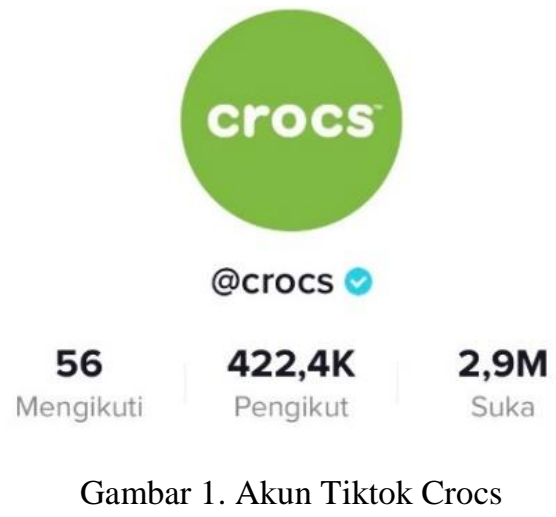

Sumber: https://vt.tiktok.com/ZSeFvpgxm/ (Akses pada 22-10-2021)

\section{Levi's}

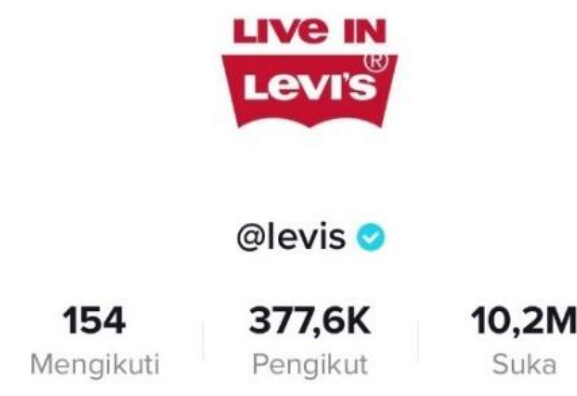

Gambar 2. Akun Tiktok Levi’s

Sumber: https://vt.tiktok.com/ZSeFvK2xd/ (Akses pada 22-10-2021) 


\section{Calvin Klein}

\section{Calvin Klein}

\section{@calvinklein $\odot$

$\begin{array}{ccc}11 & 54,3 K & 156,2 K \\ \text { Mengikuti } & \text { Pengikut } & \text { Suka }\end{array}$

Gambar 3. Akun Tiktok Calvin Klein

Sumber: https://vt.tiktok.com/ZSeFvqJAk/ (Akses pada 22-10-2021)

\section{Vessi}

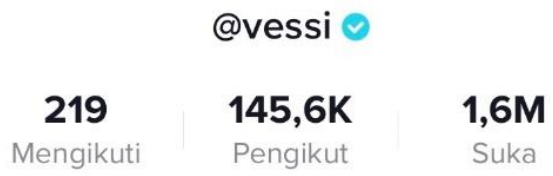

Gambar 4. Akun Tiktok Vessi

Sumber: https://vt.tiktok.com/ZSeFvq4U1/ (Akses pada 22-10-2021)

5. Gymshark
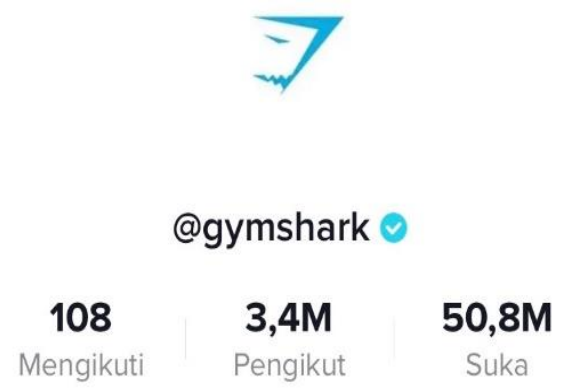

Gambar 5. Akun Tiktok Gymshark

Sumber: https://vt.tiktok.com/ZSeFvRyqW/ (Akses pada 22-10-2021) 
6. Guess

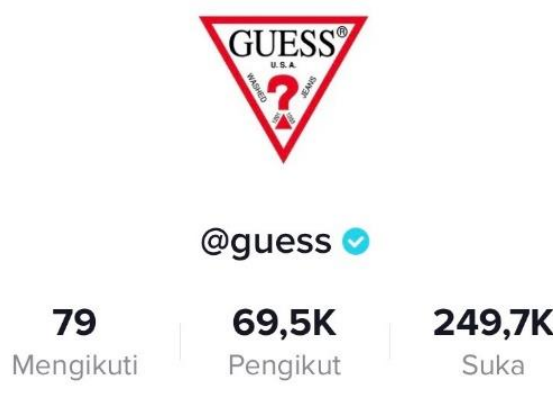

Gambar 6. Akun Tiktok Guess

Sumber: https://vt.tiktok.com/ZSeFvYb5/ (Akses pada 22-10-2021)

Dari keenam akun Tiktok 6 Brand Fashion Terkenal, peneliti menemukan nilai dari masing-masing variable yang ada untuk menghitung ratio Video Share to Likes dari setiap akun. Pada akun Tiktok terdapat 7 variabel, diantaranya:

1. Likes

2. Followers

3. Following

4. Video Likes

5. Video Share

6. Video Comments

7. Video Views

Dari ketujuh variable diatas, peneliti hanya fokus untuk menemukan hasil dari 2 variabel, yaitu:

1. Video Share

2. Likes

Dari kedua variable tersebut kemudian dianalisa sehingga menemukan nilai rata-rata dari variabel Video Share dan Likes. Untuk menghitung nilai rata-rata dari variabel Video Share dan Likes yaitu dengan cara mengambil minimal 10 postingan terbaru kemudian dihitung sehingga menemukan nilai rata-rata dari masing-masing variabel. Berikut merupakan tabel inilai rata-rata dari masing-masing brand fashion terkenal, yaitu:

Tabel 1. Analisa Rata-Rata Nilai Variabel Video Share to Likes Akun Tiktok Vessi

\begin{tabular}{|c|c|c|}
\hline No & Video Share & Likes \\
\hline 1 & 4 & 1600000 \\
\hline 2 & 0 & 1600000 \\
\hline 3 & 1 & 1600000 \\
\hline 4 & 0 & 1600000 \\
\hline 5 & 1 & 1600000 \\
\hline
\end{tabular}




\begin{tabular}{|c|c|c|}
\hline 6 & 3 & 1600000 \\
\hline 7 & 1 & 1600000 \\
\hline 8 & 7 & 1600000 \\
\hline 9 & 1 & 1600000 \\
\hline 10 & 1 & 1600000 \\
\hline TOTAL & 1.9 & 1600000 \\
\hline
\end{tabular}

Sumber: Pengolah Data Excel

Tabel 2. Analisa Rata-Rata Nilai Variabel Video Share to Likes Akun Tiktok Guess

\begin{tabular}{|c|c|c|}
\hline No & Video Share & Likes \\
\hline 1 & 60 & 249700 \\
\hline 2 & 0 & 249700 \\
\hline 3 & 0 & 249700 \\
\hline 4 & 0 & 249700 \\
\hline 5 & 12 & 249700 \\
\hline 6 & 15 & 249700 \\
\hline 7 & 6 & 249700 \\
\hline 8 & 5 & 249700 \\
\hline 9 & 6 & 249700 \\
\hline 10 & 17 & 249700 \\
\hline TOTAL & 12.1 & 249700 \\
\hline
\end{tabular}

Sumber: Pengolah Data Excel

Tabel 3. Analisa Rata-Rata Nilai Variabel Video Share to Likes Akun Tiktok Gymshark

\begin{tabular}{|c|c|c|}
\hline No & Video Share & Likes \\
\hline 1 & 822 & 50800000 \\
\hline 2 & 384 & 50800000 \\
\hline 3 & 443 & 50800000 \\
\hline 4 & 1774 & 50800000 \\
\hline 5 & 36 & 50800000 \\
\hline 6 & 7 & 50800000 \\
\hline 7 & 31 & 50800000 \\
\hline 8 & 32 & 50800000 \\
\hline 9 & 98 & 50800000 \\
\hline 10 & 216 & 50800000 \\
\hline TOTAL & 384.3 & 50800000 \\
\hline
\end{tabular}

Sumber: Pengolah Data Excel 
Tabel 4. Analisa Rata-Rata Nilai Variabel Video Share to Likes Akun Tiktok Calvin Klein

\begin{tabular}{|c|c|c|}
\hline No & Video Share & Likes \\
\hline 1 & 13 & 156200 \\
\hline 2 & 8 & 156200 \\
\hline 3 & 371 & 156200 \\
\hline 4 & 14 & 156200 \\
\hline 5 & 3 & 156200 \\
\hline 6 & 6 & 156200 \\
\hline 7 & 5 & 156200 \\
\hline 8 & 8 & 156200 \\
\hline 9 & 5 & 156200 \\
\hline 10 & 4 & 156200 \\
\hline TOTAL & 43.7 & 156200 \\
\hline
\end{tabular}

Sumber: Pengolah Data Excel

Tabel 5. Analisa Rata-Rata Nilai Variabel Video Share to Likes Akun Tiktok Levi’s

\begin{tabular}{|c|c|c|}
\hline No & Video Share & Likes \\
\hline 1 & 5 & 10200000 \\
\hline 2 & 1 & 10200000 \\
\hline 3 & 36 & 10200000 \\
\hline 4 & 38 & 10200000 \\
\hline 5 & 18 & 10200000 \\
\hline 6 & 20 & 10200000 \\
\hline 7 & 19 & 10200000 \\
\hline 8 & 20 & 10200000 \\
\hline 9 & 62 & 10200000 \\
\hline 10 & 20 & 10200000 \\
\hline TOTAL & 23.9 & 10200000 \\
\hline
\end{tabular}

Sumber: Pengolah Data Excel

Tabel 6. Analisa Rata-Rata Nilai Variabel Video Share to Likes Akun Tiktok Crocs

\begin{tabular}{|c|c|c|}
\hline No & Video Share & Likes \\
\hline 1 & 6 & 2900000 \\
\hline 2 & 8 & 2900000 \\
\hline 3 & 14 & 2900000 \\
\hline 4 & 22 & 2900000 \\
\hline 5 & 4 & 2900000 \\
\hline 6 & 1023 & 2900000 \\
\hline 7 & 24 & 2900000 \\
\hline 8 & 7 & 2900000 \\
\hline
\end{tabular}




\begin{tabular}{|c|c|c|}
\hline 9 & 304 & 2900000 \\
\hline 10 & 102 & 2900000 \\
\hline TOTAL & 151.4 & 2900000 \\
\hline
\end{tabular}

Sumber: Pengolah Data Excel

Setelah menghitung nilai rata-rata tersebut, maka akan menemukan hasil akhir nilai rata-rata dari variabel video share dan like.

Tabel 7. Nilai Variabel Pada Akun Tiktok 6 Brand Fashion Terkenal

\begin{tabular}{|c|c|c|c|c|c|c|}
\hline Variabel & Vessi & Guess & Gymshark & Calvin Klein & Levi's & Crocs \\
\hline Video Share & 1.9 & 12.1 & 384.3 & 43.7 & 23.9 & 151.4 \\
\hline Likes & 1600000 & 249700 & 50800000 & 156200 & 10200000 & 2900000 \\
\hline
\end{tabular}

Sumber: Pengolah Data Excel

Pada akun Tiktok terdapat 17 ratio yang relevan digunakan untuk mengukur kredibilitas pada masing-masing akun. Namun pada penelitian kali ini hanya berfokus pada video share to likes ratio. Untuk menghitung kredibilitas dari masing-masing akun tiktok brand fashion terkenal, peneliti menghitung dengan cara: variabel 1 dibagi dengan variabel 2, sehingga hasil analisanya akan menjadi seperti ini:

Tabel 8 \& 9. Hasil Perhitungan Ratio Akun Tiktok

\begin{tabular}{|c|c|c|c|}
\hline No & RATIO & NAMA BRAND & NILAI \\
\hline 1 & \multirow{6}{*}{$\begin{array}{c}\text { Video Share to Likes } \\
\text { Ratio }\end{array}$} & Vessi & 0.00000118750 \\
\hline 2 & & Guess & 0.00004845814977973570 \\
\hline 3 & & Gymshark & 0.000007564960629921260 \\
\hline 4 & & Calvin Klein & 0.0002797695262483990 \\
\hline 5 & & Levi's & 0.00430018532179420 \\
\hline 6 & & Crocs & 0.01814934247593470 \\
\hline
\end{tabular}

Sumber: Pengolah Data Excel

Video Share to Likes memiliki karakteristik yang tinggi, artinya semakin tinggi nilai yang dihasilkan maka semakin baik kredibilitas dari performa akun tersebut, untuk memberikan peringkat pada masing-masing brand fashion, peneliti memberikan angka 6 kepada brand yang mendapat nilai tertinggi dan angka 1 untuk brand dengan nilai terendah. Berikut tabel urutan masing-masing brand fashion: 
Tabel 10. Nilai Rasio Akun Tiktok 6 Brand Fashion Terkenal

\begin{tabular}{|c|c|c|c|c|c|}
\hline \multicolumn{7}{|c|}{ Tabel Nilai } \\
\hline Vessi & Guess & Gymshark & Calvin Klein & Levi's & Crocs \\
\hline 1 & 3 & 2 & 4 & 5 & 6 \\
\hline
\end{tabular}

Sumber: Pengolah Data Excel

Dari tabel diatas dapat disimpulkan bahwa Vessi mendapat nilai terendah untuk rasio video share to likes. Sedangkan Crocs mendapat nilai tertinggi untuk rasio ini. Jadi pada penelitian kali ini Crocs memiliki kredibilitas performa yang lebih baik dibandingkan dengan brand fashion lainnya.

\section{KESIMPULAN}

Tujuan dari penelitian ini adalah mengetahui kredibilitas performa dari akun TikTok 6 Brand Fashion Terkenal menggunakan Video Share to Likes. 6 Brand Fashion Terkenal tersebut yaitu: Vessi, Gymshark, Calvin Klein, Crocs, Guess, dan Levi's. Dari keenam Brand Fashion tersebut dapat disimpulkan bahwa:

Peringkat pertama diraih oleh Crocs dengan nilai sebesar 0.01814934247593470

Peringkat kedua diraih oleh Levi's dengan nilai sebesar 0.00430018532179420

Peringkat ketiga diraih oleh Calvin Klein dengan nilai sebesar 0.0002797695262483990

Peringkat keempat diraih oleh Guess dengan nilai sebesar 0.0000484581497797357

Peringkat kelima diraih oleh Gymshark dengan nilai sebesar 0.000007564960629921260

Peringkat keenam diraih oleh Vessi dengan nilai sebesar 0.00000118750 
Daftar Pustaka

“15 Brand Terkenal yang Menggunakan TikTok sebagai Platform Pemasaran- Maxmanroe.com”. Accessed 15 October, 2021 https://www.maxmanroe.com/brand-terkenal-yang-menggunakan-tiktok-untukpemasaran.html

Deriyanto, D., Qorib, F., Komunikasi, J. I., Tribhuwana, U., \& Malang, T. (2018). PERSEPSI MAHASISWA UNIVERSITAS TRIBHUWANA TUNGGADEWI MALANG TERHADAP PENGGUNAAN APLIKASI TIK TOK. In JISIP (Vol. 7, Issue 2). www.publikasi.unitri.ac.id

Adawiyah, D. P. R. (2020). Pengaruh Penggunaan Aplikasi TikTok Terhadap Kepercayaan Diri Remaja di Kabupaten Sampang. Jurnal Komunikasi, 14(2), 135-148. https://doi.org/10.21107/ilkom.v14i2.7504

BAGUS PRIANBODO. 2018. "PENGARUH 'TIKTOK' TERHADAP KREATIVITAS REMAJA SURABAYA,” December.

I Putu Hendika Permana, \& Ni Putu Suci Meinarni. (2021). Ratio Analysis on Tiktok (Social Media) for Qualitative Research Using Explorative Methods. Jurnal Ekonomi \& Bisnis JAGADITHA, 8(1), 30-38. https://doi.org/10.22225/jj.8.1.2944.30-38

MERI ZAPUTRI. 2021. "DAMPAK KECANDUAN MEDIA SOSIAL TIK TOK TERHADAP PERILAKU BELAJAR MAHASISWA BIMBINGAN DAN KONSELING IAIN BATUSANGKAR”

Ruth, D., \& Candraningrum, A. (n.d.). Debra Ruth, Diah Ayu Candraningrum: Pengaruh Motif Penggunaan Media Baru Tiktok terhadap Personal Branding Generasi Milenial di Instagram Pengaruh Motif Penggunaan Media Baru Tiktok terhadap Personal Branding Generasi Milenial di Instagram.

Maryam, Siti, Isrok'atun Isrok'atun, and Ani Nur Aeni. 2016. “PENDEKATAN EKSPLORATIF UNTUK MENINGKATKAN KEMAMPUAN REPRESENTASI MATEMATIS DAN KEPERCAYAAN DIRI SISWA.” Jurnal Pena Ilmiah 1 (1): 551-60. https://doi.org/10.23819/PI.V1I1.2984.

Fitrianingrum, A., \& Aruny, F. D. (2021). Strategi Promosi Media Sosial Pada Restoran Jepang Sakura $S P$ (Vol. 1, Issue 1). https://journal.uib.ac.id/index.php/concept

Kristia, S. E. (2021). PENGEMBANGAN MEDIA PROMOSI BERBASIS APLIKASI TIKTOK UNTUK MENINGKATKAN MINAT BELI PRODUK UKM DM-SEAFOOD. Jurnal Pendidikan Tata Niaga (JPTN), 9. https://covid19.go.id/ 